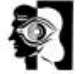

columns
KILLASPY, H. (2006) Psychiatric out-patient services: origins and future. Advances in Psychiatric Treatment, 12, 309-319.

McIVOR, R., EK, E. \& CARSON, J. (2004) Nonattendance rates among patients attending different grades of psychiatrist and a clinical psychologist within a community mental health clinic. Psychiatric Bulletin, 28, 5-7.

NEHAMA,V. S. (1969) Non-attendance at a psychiatric follow-up clinic. British Journal of Psychiatry, 115, 475-476.

* Joseph El-Khoury SpecialistTrainee in Addictions Psychiatry, Oxfordshire and Buckinghamshire Mental Health NHS FoundationTrust, Oxford Specialist CommunityAddiction Service, The Rectory Centre, Rectory Road, Oxford OX4 1BU, email:Josephelkhoury@ doctors.org.uk, Samantha Bennett Specialist Trainee in General Adult Psychiatry, South London and Maudsley Foundation NHS Trust, Adamson Centre, St Thomas' Hospital, Helen Johnston SpecialistTrainee in Psychotherapy, Surrey and Borders Partnership NHS Trust, Sarah White Division of Mental Health, St George's, University of London

doi: 10.1192/pb.32.12.473b

\section{Non-engagement and the assertive outreach team}

The concept of non-engagement lies at the heart of the Assertive Outreach Team (AOT) model (Stein \& Test, 1980).

However, in our experience there is widespread misunderstanding within mental health services about what this term means. Apart from non-engagement, the other primary criterion for acceptance into an AOT is a diagnosis of a severe and enduring mental illness, which is likely to lead to several secondary factors, including dual diagnosis, a history of selfneglect, repeated hospital admissions, chaotic lifestyle and housing problems.

Referrers often misconstrue these criteria. They see the secondary list as having equal weight as the primary, believing that AOTs specialise in working with difficult-to-manage service users, whereas in fact there is no evidence for this (Burns, 2004). Special skills of AOT staff lie in developing a good therapeutic relationship with individuals with a primary diagnosis of severe and enduring mental illness who have not engaged with the community mental health team (CMHT) at all, and this is a powerful determinant of how well a person will respond to professional input (Priebe \& Gruyters, 1993).

Referring to AOT individuals with severe mental illness who are only partially engaging with the $\mathrm{CMHT}$ on the grounds that these particular people are deemed chaotic (Burns, 2004), high-risk and hard to manage is not risk-free. Transitions between teams are known to be times of high risk for service users (e.g. increased suicide rates in individuals moved from in-patient to out-patient care; Crawford, 2004). If AOTs accept service users who are engaging with their $\mathrm{CMHT}$, they may contribute to the removal of a support network to which the person has become accustomed. It may be very difficult for service users to make the change from dealing with two or maybe three familiar individuals to as many as eight or nine unfamiliar AOT staff. Accepting inappropriate users is demoralising for members of an outreach team, who have been trained and have chosen to work with a particular, non-engaging patient group (Libberton, 2000). Not only will AOTs feel pressured to accept more such referrals, but in the process CMHTs are in real danger of becoming de-skilled.

Lastly and most importantly, individuals are likely to experience a sense of loss or rejection when transferred to an AOT with all the attendant risks of morbidity and mortality. We believe that it is vital that AOT and CMHT staff have a good, shared understanding of what is meant by the term non-engagement and that inappropriate referrals are not accepted. The Department of Health has rightly made clear that any change in emphasis to simply increase a team's number of service users by taking on people who are not suitable for AOTs should be avoided (Department of Health et al, 2005).

BURNS, T. (2004) Community Mental HealthTeams. A Guide to Current Practice. Oxford University Press.

CRAWFORD, M. J. (2004) Suicide following discharge from in-patient psychiatric care. Advances in Psychiatric Treatment, 10,434-438.

DEPARTMENT OF HEALTH, NATIONAL INSTITUTE OF MENTAL HEALTH IN ENGLAND \& CARE SERVICES IMPROVEMENT PARTNERSHIP (2005) Assertive Outreach in Mental Health in England. Report from a Day Seminar on Research, Policy and Practice. CSIP (http:// www.csip.org.uk/silo/files/ao-seminar-report.pdf).

LIBBERTON, P. (2000) Getting yourACT together. Mental Health Nursing, 20, 14-17.

PRIEBE, S. \& GRUYTERS, T. (1993) The role of the helping alliance in psychiatric community care. A prospective study. Journal of Nervous and Mental Disease, 181, 552-557.

STEIN, L. I. \& TEST, M. A. (1980) Alternative to mental hospital treatment. I. Conceptual model, treatment program, and clinical evaluation. Archives of Genera Psychiatry, 37, 392-327.

LucyToynbee Assertive Outreach Worker *Danny Allen Consultant Psychiatrist, Oxfordshire and Buckinghamshire Mental Health Partnership NHS Trust, Harlow House, Harlow Road, High Wycombe, Bucks HP13 6AA, email: danny.allen@obmh.nhs.uk doi: $10.1192 / p b .32 .12 .474$

\section{Repeat prescribing in secondary care: are there any standards?}

Repeat prescribing in secondary care mental health service has implications regarding cost, workload, service user safety and convenience. The standards available for repeat prescribing (National Prescribing Centre, 2004) apply to primary care, but there is no guidance for secondary care.
We undertook a survey of repeat prescribing practices at a community mental health team (CMHT). All psychotropic medications prescribed at the same dose on three or more consecutive appointments were considered repeat prescriptions unless otherwise specified.

Prescribing over the previous year was examined in a sample of 42 case notes. A total of $35(83 \%)$ had a clear record of which psychotropic agents were being prescribed by the $\mathrm{CMHT}$ and which ones by primary care: in 23 (66\%) of these, this was recorded in the text of the letter from a general practitioner (GP) and in 21 $(60 \%)$ it was in the list of medications at the beginning of the letter. In 20 (57\%) out of 35 case notes, this record was highlighted (bold/coloured ink). Forty individuals had received the same dose of psychotropic over at least three consecutive appointments; of these, 30 (75\%) received their repeat prescriptions from primary care, 4 (10\%) from the CMHT and in $6(15 \%)$ it was not clear who was supplying medication. Of the four individuals receiving repeats from the $\mathrm{CMHT}$, three had clear documentation of the reason for this. The total number of individual prescriptions generated as repeats by the CMHT for this sample was only four. There was a handwritten record in the notes in all of them and in two also a photocopy of the prescription(s).

We therefore recommend the following.

1. There should be a clear record, in medical notes as well as in the GP letter, stating which psychotropic agents are being prescribed by secondary care and which ones by primary care.

2. All the repeat prescriptions generated at the secondary care service should be recorded.

3. Where service funding is such that repeat prescribing budgets are directed through primary care trusts, individuals who are on a stable dose of a psychotropic agent should normally obtain repeat prescriptions from their GP.

4. Should it be appropriate to deviate from this general framework for an individual service user, the reason for this and the estimated duration of repeat prescribing of the agent by secondary care should be clearly documented and communicated to the GP.

NATIONAL PRESCRIBING CENTRE (2004) SavingTime Helping Patients. A Good Practice Guide to Quality Repeat Prescribing. NPA

Kamini Vasudev Specialist Registrar in Genera Adult Psychiatry, EIP Service, Monkwearmouth Hospital, Sunderland, *Adrian Lloyd Consultant Psychiatrist and Honorary Senior Clinical Lecturer, Wallsend Community Mental HealthTeam, Sir G.B. Hunter Memorial Hospital, The Green Wallsend, Tyne and Wear NE28 7PD, email a.j.lloyd@ncl.ac.uk, Niraj Ahuja Consultant Psychiatrist and Honorary Clinical Lecturer, Wallsend Community Mental Health Team, Sir G.B. Hunter Memorial Hospital

doi: $10.1192 / p b .32 .12 .474 a$ 